\title{
AVALIAÇÃO DA RESISTÊNCIA À CORROSÃO DE IMPLANTES EM AÇOS INOXIDÁVEIS ISO 5832-9 E F138 REMOVIDOS DE PACIENTES
}

\author{
Elison da Fonseca e Silva \\ Instituto Federal de Educação Ciência e Tecnologia Sudeste de Minas Gerais, Rua Bernardo Mascarenhas, 1283, 36080-001 \\ Juiz de Fora - MG, Brasil \\ Luiz Fernando Cappa de Oliveira* \\ Departamento de Química, Universidade Federal de Juiz de Fora, Campus Universitário, 36036-900 Juiz de Fora - MG, Brasil
}

Recebido em 14/1/11; aceito em 27/6/11; publicado na web em 3/8/11

\begin{abstract}
EVALUATION OF THE CORROSION RESISTANCE OF STAINLESS STEEL ISO 5832-9 AND F138 IMPLANTS REMOVED FROM PATIENTS. This work has compared the surfaces of two different steel samples used as orthopedical implants, classified as ASTM F138 and ISO5832-9, through optical emission spectroscopy, by means of SEM and EDS. The samples (implants) were also submitted to potentiodynamic cyclic polarization in Ringer lactate and $\mathrm{NaCl} 0.9 \mathrm{M} \mathrm{L}^{-1}$ solutions; ISO5832-9 sample did not show any kind of localized corrosion, but in the case of F138 steel was observed a pit localized corrosion in both solutions. In Ringer lactate solution it was observed a loss of about $63 \%$ for nickel and 26\% for iron for F138 stell, compared to the initial composition.
\end{abstract}

Keywords: stain steel; orthopedic implant; corrosion.

\section{INTRODUÇÃO}

Os implantes ortopédicos no Brasil são produzidos principalmente em aço inoxidável devido a dois fatores: custo mais baixo, em comparação aos metais à base de cobalto ou de titânio e suas ligas, e por apresentarem boa resistência mecânica e química. ${ }^{1}$ Atualmente os aços inoxidáveis austeníticos com maiores teores de nitrogênio têm se destacado em implantologia, por oferecerem maior resistência à corrosão e boa aceitação clínica. Estudos recentes demonstram que os aços classificados como ASTM F138, da American Society for Testing and Materials, que possuem em sua composição teores de nitrogênio na ordem de $0,02 \%$ em peso apresentaram menor resistência à corrosão localizada, se comparados aos aços com teores maiores como ocorre nos aços classificados como ISO 5832-9, da International Organization for Standardization, que apresentam cerca de $0,4 \%$ em peso. ${ }^{2} \mathrm{O}$ nióbio também apresenta um papel relevante na resistência à corrosão visto que, em teores maiores na ordem de $0,3 \%$ em peso, composição observada nos aços ISO 5832-9, a corrosão localizada na forma de pites é menor que nos casos em que esse elemento de liga não está presente, como ocorre nos aços F138. Pesquisas anteriores, com os aços ISO 5832-9 em meio de $\mathrm{NaCl}$ a $0,9 \% \mathrm{~mol} \mathrm{~L}^{-1}$, na temperatura de $36,5^{\circ} \mathrm{C}$ confirmam o papel do nióbio, presente nesse aço na composição de $0,3 \%$, conferindo-lhe maior resistência à corrosão localizada comparativamente aos aços $316 \mathrm{~L}$ e F138. ${ }^{2}$

O implante metálico, quando sofre deterioração no interior do corpo humano, pode comprometer a sua integridade mecânica e promover reações biológicas adversas no paciente implantado. Uma das formas de degradação é a corrosão, seja na forma localizada, em frestas, que afetam regiões específicas onde o fluido corpóreo fica estagnado, seja na forma de sítios aleatórios na superfície do metal denominada corrosão por pites, que aliadas aos esforços mecânicos cíclicos a que são normalmente submetidos, aceleram a liberação de partículas e íons metálicos, levando à falha prematura do implante. ${ }^{2} \mathrm{~A}$ biocompatibilidade local e sistêmica de um aço utilizado na ortopedia pode ser comprometida pelos produtos de sua corrosão, que são os responsáveis fundamentais pela vida útil do implante.

*e-mail: luiz.oliveira@ufjf.edu.br
A resistência à corrosão dos aços inoxidáveis deve-se majoritariamente à formação de um filme fino superficial, camada passiva, em cuja composição apresenta essencialmente óxidos e hidróxidos dos principais metais presentes na liga. Os aços inoxidáveis apresentam em sua composição química elevados teores de crômio, o principal responsável pela formação da camada passiva, ou seja, o crômio é determinante para o aumento da resistência à corrosão. Sourisseau ${ }^{3}$ afirma que o teor de crômio presente no óxido é proporcional ao presente na liga e teores superiores a $13 \%$ geram filmes passivos, compostos basicamente de hidróxido de cromo hidratado. Esta camada fina por ser aderente à superfície do metal inibe o processo de corrosão, mantendo a liberação de íons em níveis muito baixos. Esses aços apresentam, no entanto, suscetibilidade à corrosão localizada, embora apresentem boa resistência à corrosão generalizada (corrosão uniforme sobre toda a superfície). A presença de nitrogênio, intersticialmente alocado na célula unitária cúbica de face centrada dos aços inoxidáveis austeníticos aplicados em implantes, mesmo em pequenas porcentagens, confere um aumento significativo na resistência à corrosão por pites e frestas, além de promover uma melhoria significativa nas propriedades mecânicas. Esse efeito é observado no aço inoxidável do tipo ISO 5832-9, que apresenta maior teor de nitrogênio em sua composição, conferindo-lhe melhores propriedades mecânicas e químicas, sendo apontado como o substituto do aço inoxidável F138, principalmente em implantes que requerem longos períodos de permanência no corpo humano. ${ }^{4}$

Um dos ensaios eletroquímicos que possibilitam caracterizar a resistência à corrosão por pites através da observação do potencial crítico de pite $\left(\mathrm{E}_{\mathrm{c}}\right)$, bem como o potencial de repassivação são especificados pelas normas ASTM G3-94 e ASTM G15-95, é denominado ensaio de polarização cíclica potenciodinâmica; tal ensaio permite ainda o levantamento da curva de polarização do metal na solução de ensaio. Tais curvas mostram a propensão do material ensaiado à corrosão localizada, visto que a formação de pites diminui com o aumento do potencial crítico $\mathrm{E}_{\mathrm{c}}$; deduz-se também pela curva de polarização a densidade de corrente de passivação (Ip), que mostra a capacidade de proteção do filme passivo: quanto menor o Ip maior será a proteção do filme passivo sobre a superfície da liga.

Estudos realizados nos Estados Unidos mostram que aproxima- 
damente $10 \%$ dos dispositivos destinados a osteossíntese que foram removidos cirurgicamente de pacientes, por apresentarem quadros adversos, se mostraram fora das especificações das normas ASTM. Esses dados no Brasil são praticamente inexistentes, ou seja, não há acompanhamento no tocante ao atendimento às normas brasileiras vigentes. Assim, um implante quando removido de um paciente não passa por nenhum processo investigativo que busque relacionar a causa da remoção com as propriedades do material utilizado na sua fabricação. ${ }^{5}$

O objetivo deste trabalho foi avaliar a resistência à corrosão localizada de aços utilizados na fabricação dos implantes removidos de pacientes afetados por quadros inflamatórios na região dos mesmos, submetendo-os ao ensaio de polarização cíclica potenciodinâmica, em seguida comparando suas superfícies por microscopia eletrônica de varredura (MEV), após aplicação de potencial de $50 \mathrm{mV}$ acima do potencial da elevação da corrente, na perspectiva de associar os resultados obtidos com uma das possíveis causas do insucesso da inserção do implante no organismo do paciente.

\section{PARTE EXPERIMENTAL}

Os materiais estudados neste trabalho foram os aços inoxidáveis de implantes removidos cirurgicamente de pacientes, sendo agrupados da seguinte forma: 1 placa autodinâmica removida de paciente após 18 meses da implantação (Figura 1A); 4 parafusos aleolar $\emptyset 4,5$ mm removidos de paciente após 18 meses da implantação (Figura 1B); 4 parafusos esponjosos $\varnothing 6,5$ rosca total sem identificação do tempo de uso (Figura 1C); 2 hastes femorais de prótese total do quadril removidas de pacientes após 24 e 18 meses da implantação (Figura 1D). Em nenhum dos implantes havia qualquer tipo de identificação do fabricante. Todos os implantes foram removidos devido ao desenvolvimento de quadro inflamatório em seus portadores. Para limpeza e remoção do material orgânico aderido à superfície dos implantes, foi utilizado lavador ultrassom Embrasol modelo LS $1,8 \mathrm{D}$ com acetona.

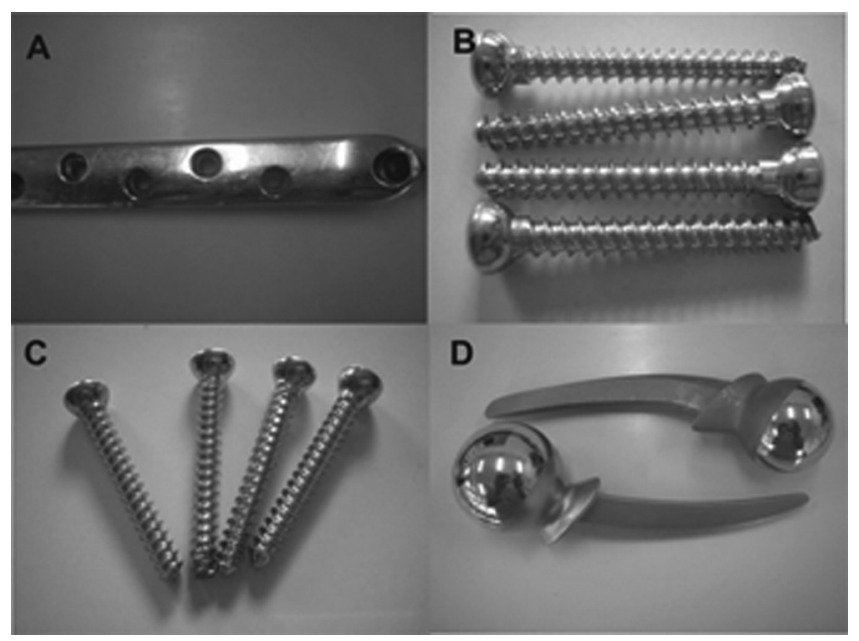

Figura 1. Implantes removidos cirurgicamente de pacientes

As análises químicas dos aços empregados na fabricação dos implantes foram realizadas em amostras sólidas em espectrômetro de emissão óptica marca ARL 3460- 2000 Metals Analyzer; para tal, os implantes foram cortados em cortadeira de amostra metalográfica - marca Pantec - mod. Pancut-40.

Os ensaios de polarização cíclica potenciodinâmica foram efetuados conforme as normas ASTM G3-94 e ASTM G15-95 em amostras dos aços, obtidas através de cortes dos implantes, sem qualquer tipo de tratamento térmico ou termoquímico. Posteriormente, foram prepa- rados eletrodos embutidos em resina acrílica autopolimerizável, após contato elétrico da amostra com fio de cobre realizado por soldagem com chumbo. As amostras montadas como eletrodos de trabalho, em configurações geométricas distintas, foram lixadas até atingirem área exposta de $1 \mathrm{~cm}^{2}$, idêntica em todos os eletrodos. Para tanto, foram utilizadas lixas de carbeto de silício ( $\mathrm{SiC}$ ), de granulometrias 120, 320, $360,400,500,600,800,1200$ e 2000 e a pasta de diamante de $1 \mu \mathrm{m}$ para obtenção de uma superfície polida. Para aplicação do potencial e registro da corrente de corrosão foi utilizado um potenciostato Autolab 20 acoplado a um microcomputador. Como eletrodo de referência utilizou-se o do tipo calomelano saturado (ECS) e o contraeletrodo de platina. Os corpos de prova foram imersos no eletrólito $1 \mathrm{~h}$ antes do início da aplicação do potencial, para atingir o potencial de equilíbrio. A taxa de varredura de potencial foi de $0,33 \mathrm{mV} / \mathrm{s}(1,2 \mathrm{~V} / \mathrm{h})$ e o potencial de reversão ocorria quando a densidade de corrente atingia o valor de $100 \mu \mathrm{A} / \mathrm{cm}^{2}$. As amostras foram submetidas a um potencial de $50 \mathrm{mV}(\mathrm{ECS})$ mais elevado do que o potencial crítico de pite $\left(\mathrm{E}_{\mathrm{c}}\right)$ para ambos os eletrodos. Depois de ensaiadas, as amostras foram retiradas das soluções e lavadas com ultrassom em água deionizada e, em seguida, banhadas em acetona e secas em jato de ar quente. Os testes foram conduzidos em solução de $\mathrm{NaCl} 0,9 \mathrm{~mol} \mathrm{~L}^{-1}$ a $37{ }^{\circ} \mathrm{C}$ e solução de Ringer Lactato, constituído de 0,3 g/100 mL de lactato de sódio, 0,6 $\mathrm{g} / 100 \mathrm{~mL}$ de cloreto de sódio, $0,03 \mathrm{~g} / 100 \mathrm{~mL}$ de cloreto de potássio e $0,02 \mathrm{~g} / 100 \mathrm{~mL}$ de cloreto de cálcio, na mesma temperatura, em célula eletrolítica de três eletrodos. As soluções de $\mathrm{NaCl} 0,9 \mathrm{~mol} \mathrm{~L}^{-1}$ e de Ringer Lactato foram escolhidas para serem os eletrólitos nos ensaios eletroquímicos por serem amplamente empregadas pela medicina para reposição de fluidos corporais extracelulares, devido suas características eletroquímicas e por serem soluções isotônicas ao plasma sanguíneo.

Durante o ensaio eletroquímico, em solução de Ringer Lactato, houve a formação de um precipitado sólido, e para conhecer a composição desse produto obtido neste ensaio, os aços F138 e ISO 5832-9 foram novamente ensaiados em solução de Ringer Lactato, obedecendo ao mesmo procedimento adotado para a traçagem das curvas de polarização potenciodinâmica e para o preparo dos eletrodos. O tempo de ensaio foi adotado, por comodidade operacional, em 4, 16 e 64 h e o volume de solução foi arbitrariamente estipulado em $20 \mathrm{~mL}$ para cada período.

Após cada período de ensaio a solução foi separada e se iniciou novo ciclo com novos eletrodos de trabalho e com nova solução de Ringer Lactato. Nas três soluções correspondentes aos tempos de 4, 16 e $64 \mathrm{~h}$ de ensaio foi medido o $\mathrm{pH}$ de cada uma delas. Tais amostras líquidas foram filtradas a seco e o resíduo retido no papel de filtro foi removido para bécher, lavado com água deionizada, seco e medido. Este resíduo foi dissolvido com $\mathrm{HNO}_{3}$ a $5 \%$, transferido para balão e avolumado; com este procedimento, obteve-se a massa de resíduo/volume. Em seguida foi filtrado e os resíduos sólidos foram analisados por espectroscopia de emissão ótica com plasma acoplado indutivamente - ICP-OES - Última 2 fabricante Horiba Jobin Yvon.

As medidas de microscopia eletrônica de varredura foram efetuadas em equipamento marca LEO S440, equipado com detector de elétrons retroespalhados e elétrons secundários para se verificar as características do ataque corrosivo. O MEV utilizado dispõe ainda de um sistema de microanálise por dispersão de energia (EDS) Link ISIS L300 com detector de SiLi Pentafet, janela ultrafina ATW II, de resolução aferida de $128 \mathrm{eV}$ para $5,9 \mathrm{keV}$. A resolução da microanálise por EDS é da ordem de $1 \mu \mathrm{m}$ de raio em superfície e uma profundidade da ordem de 1,5 a $5 \mu \mathrm{m}$, dependendo da densidade do material no ponto analisado. Essa técnica foi aplicada buscando conhecer as prováveis mudanças na composição química dos aços em estudo, devido a possíveis reações de oxidação na superfície das amostras, após o ensaio eletroquímico e confrontar seus efeitos com as curvas de polarização cíclica potenciodinâmica. 


\section{RESULTADOS E DISCUSSÃO}

Na Tabela 1 são mostrados os valores percentuais máximos em termos de composição química definidos pelas normas ASTM F13892 e ISO 5832-9:2008. Além disto, a mesma Tabela 1 apresenta os resultados de análise química efetuada através de espectrometria de emissão ótica. Tais resultados mostram que ambos os tipos de ligas usadas estão dentro dos parâmetros aceitáveis de composição química.

Visto que os implantes estudados não apresentavam nenhuma identificação do fabricante e do tipo de aço empregado em suas fabricações, a composição química obtida por espectroscopia de emissão ótica permitiu identificar os tipos de aços utilizados. Os materiais das hastes femorais de prótese total do quadril foram identificados como aço F138, bem como os parafusos maleolar $\varnothing 4,5 \mathrm{~mm}$ e os parafusos esponjosos $\emptyset 6,5 \mathrm{~mm}$ rosca total. A placa autodinâmica apresentou composição química característica à dos aços ISO 5832-9. A Tabela 1 mostra os teores observados nos implantes e compara-os com os valores recomendados pelas normas. Por esta tabela é possível observar que os teores de nitrogênio, crômio, níquel e molibdênio encontrados no aço da placa autodinâmica - PA está em conformidade com a norma ISO 5832-9. As demais peças foram produzidas com aços cuja composição se enquadra à norma ASTM F 138. Conforme observado nesta tabela, os teores de carbono ao se apresentarem com valores máximos indicados pelas normas garantem a estabilidade do crômio e evitam a formação do composto $\mathrm{Cr}_{23} \mathrm{C}_{6}$ que consome muito crômio em sua formação, o que acarreta consequentemente no empobrecimento desse elemento na matriz, e uma perda das características de resistência à corrosão própria do aço inoxidável. Destaca-se ainda que teores mais baixos de silício, manganês, fósforo e enxofre, como os apresentados na Tabela 1 para a norma ASTM F138 são condições necessárias na composição deste tipo de aço a fim de que sejam garantidas suas propriedades físico-químicas. ${ }^{4}$

O níquel é um importante elemento de adição ao aço inoxidável cuja função, além do aumento da resistência à corrosão, é estabilizar a austenita, microestrutura de fácil trabalhabilidade mecânica e boa resistência à corrosão. Nas peças estudadas os teores de níquel, mostrados na Tabela 1, se apresentaram em conformidade com os parâmetros considerados pelas normas adotadas para composição química, em relação à ISO 5832-9 indica teores de níquel menores $(9,00-11,00 \%)$ e à norma da ASTM para a liga F138 $(13,00-15,00 \%)$, dessa forma, apenas a placa autodinâmica apresentou um teor de níquel $(10,98 \%)$ conforme os padrões estabelecidos pela norma ISO 5832-9. Quanto aos demais aços das peças analisadas concluiu-se que se encontram em conformidade com a norma ASTM F138. ${ }^{4}$
O teor de crômio apresentado na placa autodinâmica também se enquadra na norma ISO e as outras peças segundo a norma ASTM. Esses valores observados para o crômio, em todos os implantes estudados, garantem boas propriedades para a formação da camada passiva com espessura e características adequadas à utilização como biomaterial, visto que os aços que apresentam uma porcentagem maior deste elemento também irão apresentar uma camada passiva com maior resistência diante dos processos corrosivos. Os teores de molibdênio apresentaram-se em conformidade com as normas adotadas em todas as peças. Este elemento químico na proporção indicada pelas normas apresentadas na Tabela 1 confere aumento na resistência à corrosão localizada. ${ }^{4}$ Em última análise, todos os aços inoxidáveis utilizados na produção das peças estudadas apresentaram composição química dentro das faixas estabelecidas pelas normas de referência para composição química.

Os ensaios de polarização cíclica potenciodinâmica foram realizados com o objetivo de se obter informações sobre a resistência à corrosão por pite, verificando-se a estabilidade da camada passiva formada sobre a superfície do aço e, ainda, verificar comparativamente, a suscetibilidade à corrosão localizada das ligas estudadas. A partir do trabalho de Terada ${ }^{6}$ que afirma existir no aço inoxidável, durante o ataque eletroquímico, a precipitação de uma fina camada de consistência gelatinosa na superfície dos eletrodos ensaiados com a superfície exposta na posição horizontal interferindo na formação dos pites, optou-se para a realização de todos os testes com a configuração de célula, onde o eletrodo de trabalho é montado com a área exposta na posição vertical, independente do meio eletrolítico adotado.

As curvas obtidas nos ensaios eletroquímicos são apresentadas na Figura 2, que se subdivide em duas partes (A e B) representando, respectivamente, a imersão em $\mathrm{NaCl}$ e em solução de Ringer Lactato. Sendo assim, os eletrodos de trabalho, um para o aço F138 e outro para o ISO 5832-9, ambos com área de $1 \mathrm{~cm}^{2}$, foram ensaiados primeiramente em solução $\mathrm{NaCl} 0,9 \mathrm{~mol} \mathrm{~L}^{-1}$. A conduta do aço F138, representada pela curva da Figura 2A, se mostrou conforme o esperado, ou seja, comportamento característico de materiais que apresentam potencial crítico de pite, $\mathrm{E}_{\mathrm{c}}$, bem definido $\left[\mathrm{E}_{\mathrm{c}}=568 \pm\right.$ $15 \mathrm{mV}(\mathrm{ECS})]$. A quebra da passividade do material pela nucleação e propagação estável de um ou mais pites de corrosão é definida por esse parâmetro, que representa o potencial máximo acima do qual ocorre o processo corrosivo caracterizado pela nucleação de pites, e é assinalado por um aumento acentuado da densidade de corrente de corrosão, localizado em uma pequena região da superfície. A histerese observada na Figura 2A representa a varredura da corrente em sentido contrário e demonstra o fenômeno característico deste aço, o da corrosão por pites. Os pites que foram nucleados a partir do potencial

Tabela 1. Composição química dos aços segundo as normas ASTM F138 e ISO 5832-9 e composição observada nos implantes removidos

\begin{tabular}{|c|c|c|c|c|c|c|c|c|c|}
\hline \multirow{2}{*}{ Elemento } & \multicolumn{2}{|c|}{ Normas } & \multicolumn{5}{|c|}{ Composição química observada nas peças } & \multirow{2}{*}{$\begin{array}{c}\text { \% em peso } \\
\text { microrregião HF1 }\end{array}$} & \multirow{2}{*}{ Variação } \\
\hline & ASTM F138-92 & ISO 5832-9 & PA & PM & $\mathrm{PE}$ & HF1 & $\mathrm{HF} 2$ & & \\
\hline Carbono & 0,03 máx. & 0,08 máx. & 0,017 & 0.03 & 0,011 & 0,011 & 0,017 & & \\
\hline Silício & 0,75 máx. & 0,75 máx. & 0,16 & 0,53 & 0,47 & 0,25 & 0,16 & & \\
\hline Manganês & 2,00 máx. & $2,00-4,25$ & 1,98 & 1,83 & 1,92 & 1,89 & 1,79 & & \\
\hline Fósforo & 0,025 máx. & 0,025 máx. & 0,013 & 0,023 & 0,024 & 0,025 & 0,013 & & \\
\hline Enxofre & 0,01 máx. & 0,010 máx. & 0,0018 & 0,002 & 0,002 & 0,009 & 0,001 & & \\
\hline Cobre & 0,50 máx. & 0,25 máx. & 0,06 & 0,05 & 0.057 & 0,048 & 0,06 & & \\
\hline Níquel & $13,00-15,00$ & $9,00-11,0$ & 10,98 & 13 & 14,19 & 14,4 & 14,3 & 5,279 & $-63 \%$ \\
\hline Crômio & $17,00-19,00$ & $19,50-22,00$ & 20,55 & 17,6 & 17,48 & 17,51 & 17,31 & 44,41 & $254 \%$ \\
\hline Molibdênio & 2,00 a 3,00 & 2,0 a 3,0 & 2,44 & 2,4 & 2,18 & 2,11 & 2,8 & & \\
\hline Ferro & Balanço & Balanço & Bal. & Bal. & Bal. & Bal. & Bal. & 47,36 & $-63 \%$ \\
\hline Nitrogênio & 0,10 máx. & $0,25-0,50$ & 0,35 & 0,036 & 0,08 & 0,037 & 0,045 & & \\
\hline
\end{tabular}

PA - Placa autodinâmica; PM - Parafusos Maleolar Ø 4,5 mm; PE - Parafusos esponjosos Ø 6,5 rosca total; HF 1e HF 2 - Hastes femorais. 

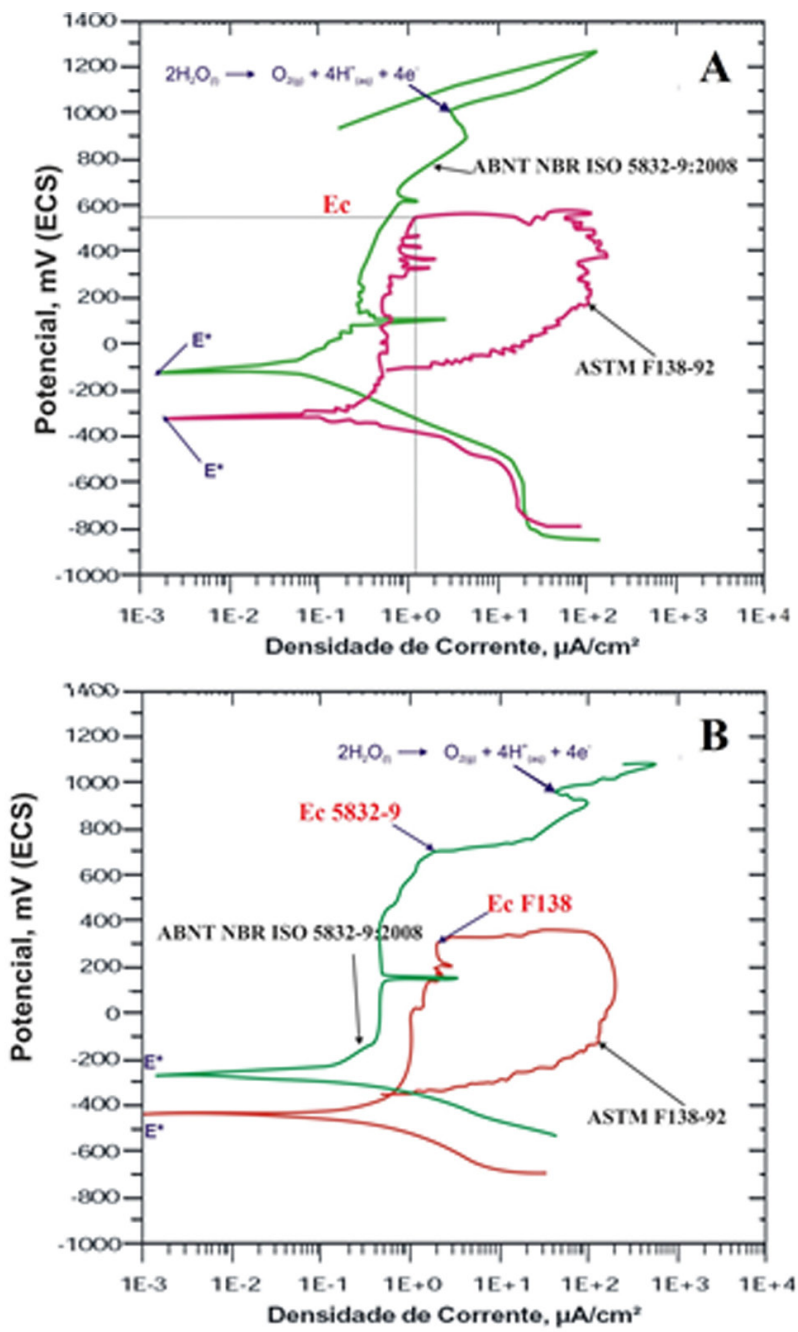

Figura 2. Curvas representativas obtidas em ensaio de polarização cíclica potenciodinâmica para os aços ASTM F138 e ISO 5832-9. A) Em solução de $\mathrm{NaCl}$ 0,9 mol L $L^{-1}$ na temperatura de $37^{\circ} \mathrm{C}$. B) Em solução de Ringer Lactato na temperatura de $37^{\circ} \mathrm{C}$

crítico $\left(\mathrm{E}_{\mathrm{c}}\right)$ são representados pela histerese na curva de polarização e caracterizam aqueles pites que não chegam a repassivar, mesmo para valores inferiores ao $\mathrm{E}_{\mathrm{c}}$ quando da reversão no sentido da varredura. Segundo Giordani, ${ }^{7}$ quando a histerese corta a curva desenvolvida durante a varredura no sentido crescente define o potencial de proteção (Ep), abaixo do qual os pites nucleados são repassivados. Por outro lado, Cahoon ${ }^{8}$ observa que a diferença entre o potencial crítico de pite e o potencial de proteção $\left(E_{c}-E p\right)$ representa a resistência à corrosão em frestas de um material. Esta diferença é mostrada na Figura 2A como o tamanho da histerese formada na curva de polarização que, além da resistência à corrosão em fresta do material, indica ainda a capacidade do material de se repassivar após iniciada a corrosão localizada no interior do pite durante seu crescimento estável. ${ }^{8}$ Assim, a região da histerese representa o crescimento dos pites que tiveram sua nucleação iniciada no potencial crítico $\left(\mathrm{E}_{\mathrm{c}}\right)$ e não atingiram, como se espera, a repassivação ao alcançarem potenciais menores que o crítico após a reversão no sentido da corrente. ${ }^{9}$

Ainda relativo à solução de $\mathrm{NaCl}$ observou-se um comportamento diferente para o aço classificado como ISO 5832-9, cujo potencial crítico de pite $\left(\mathrm{E}_{\mathrm{c}}\right)$ não foi atingido. A curva traçada para este aço durante o ensaio, também mostrada na Figura 2A, ao atingir um potencial próximo a $1000 \mathrm{mV}(\mathrm{ECS})$ apresentou um aumento na densidade de corrente. Alguns autores afirmam que este valor de potencial leva à reação de desprendimento de oxigênio (RDO), de acordo com a reação:

$$
2 \mathrm{H}_{2} \mathrm{O} \rightarrow \mathrm{O}_{2}+4 \mathrm{H}^{+}+4 \mathrm{e}^{-}
$$

Tal potencial impede distinguir se este aumento repentino na densidade de corrente é devido a esta reação na superfície do metal ou à corrente derivada da nucleação de pites. Esta insegurança na interpretação dos resultados limita a utilização deste tipo de ensaio a potenciais mais baixos. ${ }^{10}$

Comparando-se os resultados fica evidente que, devido ao seu valor de potencial crítico de pite $\left(\mathrm{E}_{\mathrm{c}}\right)$, a amostra constituída de aço ISO 5832-9 apresenta uma resistência à corrosão localizada superior à do aço $\mathrm{F} 138$, em solução de $\mathrm{NaCl} 0,9 \mathrm{~mol} \mathrm{~L}^{-1}$. Este desempenho é caracterizado pelo teor de nitrogênio observado no aço ISO 5832-9 da placa autodinâmica $(0,35 \%$ em massa), enquanto que nos outros implantes tal valor não chegou a $0,01 \%$. O nitrogênio é quimicamente dissolvido na estrutura cristalina da austenita, constituindo uma solução sólida intersticial; ${ }^{11}$ com isso tem-se um aumento na estabilidade da austenita e, também, um aumento da resistência mecânica e à corrosão por pite. O teor de crômio também é fator determinante na estabilidade química da camada passiva, ou seja, contribui para o aumento da resistência à corrosão do aço inoxidável. Assim, o melhor desempenho observado para peças do aço ISO 5832-9 pode ser atribuído também por apresentar uma maior porcentagem de crômio dissolvido na liga em relação ao F138; tais valores correspondem a 20,55 e $17,5 \%$, respectivamente.

Os valores de potencial de circuito aberto estacionário ( $\left.\mathrm{E}^{*}\right)$, determinados para os aços estudados nas duas soluções, são mostrados na Tabela 2. Este parâmetro é uma medida do comportamento da corrosão "natural" do sistema em estudo, na ausência de indução de potenciais ou correntes externas. Valores mais positivos de $\mathrm{E}^{*}$ sugerem a tendência a uma maior resistência à corrosão do metal, visto que para metais em meio aquoso é também chamado de potencial de corrosão ( $\left.\mathrm{E}_{\text {corr }}\right)$, onde a corrosão está ocorrendo naturalmente. Assim, quanto mais baixo se apresenta o $\mathrm{E}_{\text {corr }}$ mais rapidamente o metal inicia o processo de corrosão. ${ }^{12}$ Pela Tabela 2 o valor de E* para o aço F138, mais negativo que o do aço ISO 5832-9, é um indicativo adicional da superior resistência à corrosão do segundo em relação ao primeiro aço.

Em solução de Ringer Lactato as curvas traçadas estão representadas na Figura 2B, na qual o comportamento de ambos os aços foi marcado por corrosões localizadas mais significativas. O aço F 138 foi caracterizado por apresentar um $\mathrm{E}_{\mathrm{c}}$ a um potencial mais baixo que na solução $\mathrm{NaCl} 0,9 \mathrm{~mol} \mathrm{~L}^{-1}$. Por esta figura percebe-se uma queda no potencial crítico Ec, cujo valor é $568 \pm 15 \mathrm{mV}$ (ECS), identificado na Figura $2 \mathrm{~A}$, sendo reduzido para $110 \pm 15 \mathrm{mV}$ (ECS), como mostra a Figura 2B. É notória a similaridade entre as duas curvas das Figuras 2A e 2B para o aço F138; entretanto, observa-se pela Figura 2B que na solução de Ringer Lactato houve um deslocamento da curva para níveis de potenciais mais baixos, o que deixa claro o maior efeito corrosivo desta solução em relação à de $\mathrm{NaCl}$.

Como observado anteriormente, em solução de $\mathrm{NaCl} 0,9$ mol $\mathrm{L}^{-1}$, o aço ISO 5832-9 não apresenta potencial crítico de pite $\left(\mathrm{E}_{\mathrm{c}}\right)$, potencial que caracteriza a nucleação de pites. Entretanto, na solução de Ringer Lactato houve um acréscimo acentuado na densidade de corrente quando o potencial atingiu valores próximos a $500 \pm 15$ $\mathrm{mV}$ (ECS), indicando assim o surgimento de nucleação de pites; em outras palavras, o aparecimento do potencial crítico de pite $\left(\mathrm{E}_{\mathrm{c}}\right)$ também para o aço ISO 5832-9 indica a ocorrência do rompimento da camada passiva. Pelo exposto na Tabela 2, os valores de E* para os dois aços apresentam-se mais negativos em solução de Ringer Lactato, ratificando a maior agressividade corrosiva desta solução, conforme o trabalho de Terada. ${ }^{6}$ 
Tabela 2. Potenciais críticos de pite $\left(\mathrm{E}_{\mathrm{c}}\right)$, potenciais de proteção $(\mathrm{Ep})$ e potenciais de circuito aberto ( $\left.\mathrm{E}^{*}\right)$ para os aços inoxidáveis ISO $5832-9$ e $\mathrm{F} 138$ em solução de $\mathrm{NaCl} 0,9 \mathrm{~mol} \mathrm{~L}^{-1}$ e solução de Ringer Lactato

\begin{tabular}{llccc}
\hline Solução & Aço & $E_{\mathrm{c}} \mathrm{mV}(\mathrm{ECS})$ & Ep mV(ECS) & $\mathrm{E}^{*} \mathrm{mV}(\mathrm{ECS})$ \\
\hline NaCl 0,9 mol L & & $-4 \pm 146$ & $-305 \pm 15$ \\
& F 138 (Haste Femoral 1) & $568 \pm 15$ & -- & $-1 \pm 5$ \\
\multirow{2}{*}{ Ringer Lactato } & ISO5832-9 (Placa Autodinâmica) & $>800 \pm 0$ & $-400 \pm 110$ & $-420 \pm 20$ \\
& F 138 (Haste Femoral 1) & $110 \pm 15$ & -- & $-280 \pm 20$ \\
\hline
\end{tabular}

Na Figura 3 são apresentados os resultados obtidos por MEV empregando imagem de elétrons secundários, nos dois tipos de aços utilizados na fabricação dos implantes estudados, depois do ensaio de polarização cíclica potenciodinâmica. O aço F138 representado pela haste femoral 1 e o aço ISO 5832-9 representado pela placa autodinâmica, que foram submetidos ao ensaio em meio de $\mathrm{NaCl}$ 0,9 $\mathrm{mol} \mathrm{L}^{-1}$, apresentaram comportamentos distintos, conforme é mostrado na Figura 3A relativa ao aço F138 e na Figura 3B relativa ao aço ISO 5832-9. Os resultados do mesmo ensaio realizado nestas amostras em solução de Ringer Lactato são apresentados na Figura 3C para o F138 e Figura 3D para o ISO 5832-9. É importante ressaltar que o aço F138 apresentou pites nas duas soluções (Figuras 3A e 3C), enquanto que no aço ISO5832-9 a nucleação de pites foi detectada apenas na solução de Ringer Lactato, confirmando os resultados do ensaio de polarização cíclica potenciodiâmica; tais resultados sugerem uma maior agressividade da solução de Ringer Lactato, visto que se observou ainda neste meio uma maior concentração de pites no aço F138 conforme mostram as Figuras 3A e 3C. As análises por MEV vêm assim confirmar todas as medidas eletroquímicas obtidas nos ensaios de polarização cíclica potenciodinâmica, em ambas as

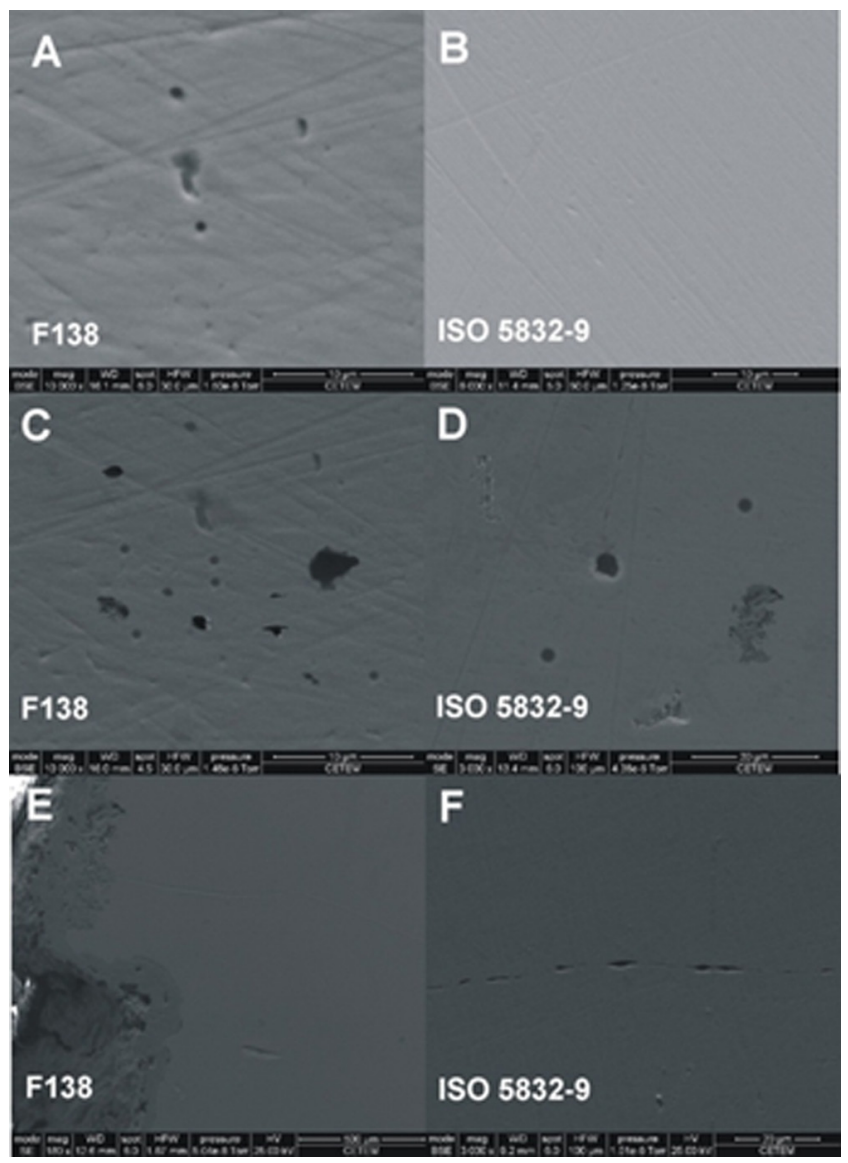

Figura 3. Análise da superfície das amostras obtidas por MEV através de elétrons secundários dos aços ISO 5832-9 e ASTM F138 submetidas a ensaios de polarização cíclica em solução de $\mathrm{NaCl} 0,9 \mathrm{~mol} \mathrm{~L}^{-1}$ e Ringer Lactato soluções tanto para o aço F138 quanto para o aço ISO 5832-9. Na solução de Ringer Lactato a nucleação de pites no potencial $\mathrm{E}_{\mathrm{C}}$ para o ISO 5832-9 se deu no potencial $700 \pm 15 \mathrm{mV}$ (ECS) em destaque na Figura 2B, resultado comprovado pela imagem de MEV que mostra os pites nucleados nesta liga (Figura 3D). Para o aço F138, em solução de Ringer Lactato, o aumento da concentração de pites mostrado na Figura $3 \mathrm{C}$, está em consonância com a medida de $\mathrm{E}_{\mathrm{C}}$ mostrado na Figura 2C, cujos valores são mais baixos $310 \pm 15 \mathrm{mV}$ (ECS), comparados aos $568 \pm 15 \mathrm{mV}$ (ECS) registrados na solução de $\mathrm{NaCl}$ 0,9 mol $\mathrm{L}^{-1}$. A queda no valor de $\mathrm{E}_{\mathrm{c}}$ observado na solução de Ringer Lactato para o aço F138 representa a confirmação eletroquímica da maior agressividade desta solução em comparação à de $\mathrm{NaCl} 0,9 \mathrm{~mol} \mathrm{~L}{ }^{-1}$.

Uma micrografia da haste femoral 1, no estado como recebido, é apresentada na Figura 3E, onde a imagem obtida pelo MEV evidencia o acentuado processo de corrosão no aço F138 com significativa perda de material metálico na forma iônica que foi, possivelmente, liberado para o organismo do paciente segundo a reação proposta por Sedriks. ${ }^{13}$

$\mathrm{M}+\mathrm{H}^{+} \rightarrow \mathrm{M}^{+}+1 / 2 \mathrm{H}_{2}$ (onde $\mathrm{M}$ representa o metal)

Segundo este autor, a elevada concentração de ions $\mathrm{H}^{+}$(e um consequente $\mathrm{pH}$ baixo) no interior do pite deve ser a causa do mecanismo autocatalítico de degradação do metal. Já a Figura 3F mostra a imagem de MEV do aço ISO 5832-9 da placa autodinâmica conforme o recebimento e caracteriza uma área onde pites foram desenvolvidos, porém em quantidades inferiores às observadas na liga F138. Não foram encontrados em nenhuma região do aço ISO 5832-9 processos corrosivos tão intensos como o apresentado na Figura 3E, que corresponde ao aço F138 da haste femoral 1 com intenso processo de corrosão generalizada, ocorrida no organismo do paciente portador deste implante.

Na Figura 4 podem ser observados os resultados de EDS em regiões de uma amostra do aço F138 da haste femoral 1, atacado eletroliticamente em solução de Ringer Lactato. A Figura 4A identifica um sítio com corrosão generalizada próxima a um pite. Nesta região foi realizado um mapeamento EDS para os elementos enxofre e crômio, como mostra a Figura 4B. Os valores percentuais também foram obtidos por análise quantitativa através de EDS, na região de interesse da amostra, com os resultados mostrados na Tabela 1. Comparando os valores desta Tabela representados na coluna HF1 (haste femoral 1) com os valores observados pela técnica de EDS, após o ensaio eletroquímico, observa-se que houve uma variação significativa em todos os elementos químicos mensurados. Dentre as alterações, o crômio apresentou um acréscimo de mais de $250 \%$ na concentração; já o ferro e o níquel apresentaram uma redução de 26 e $63 \%$, respectivamente, em seus teores. Tal redução nos teores de ferro e níquel é um forte indicativo de que ambos os elementos foram liberados da superfície da liga para o meio (solução Ringer Lactato), onde, por efeitos físico-químicos, houve formação de precipitados envolvendo esses metais e o lactato. Quanto ao crômio, o acréscimo identificado na análise deve-se à redução percentual dos elementos ferro e níquel.

Na Figura 4C pode ser observado o mapa EDS de outra região da amostra em relação à presença de oxigênio, e neste sítio foi de- 


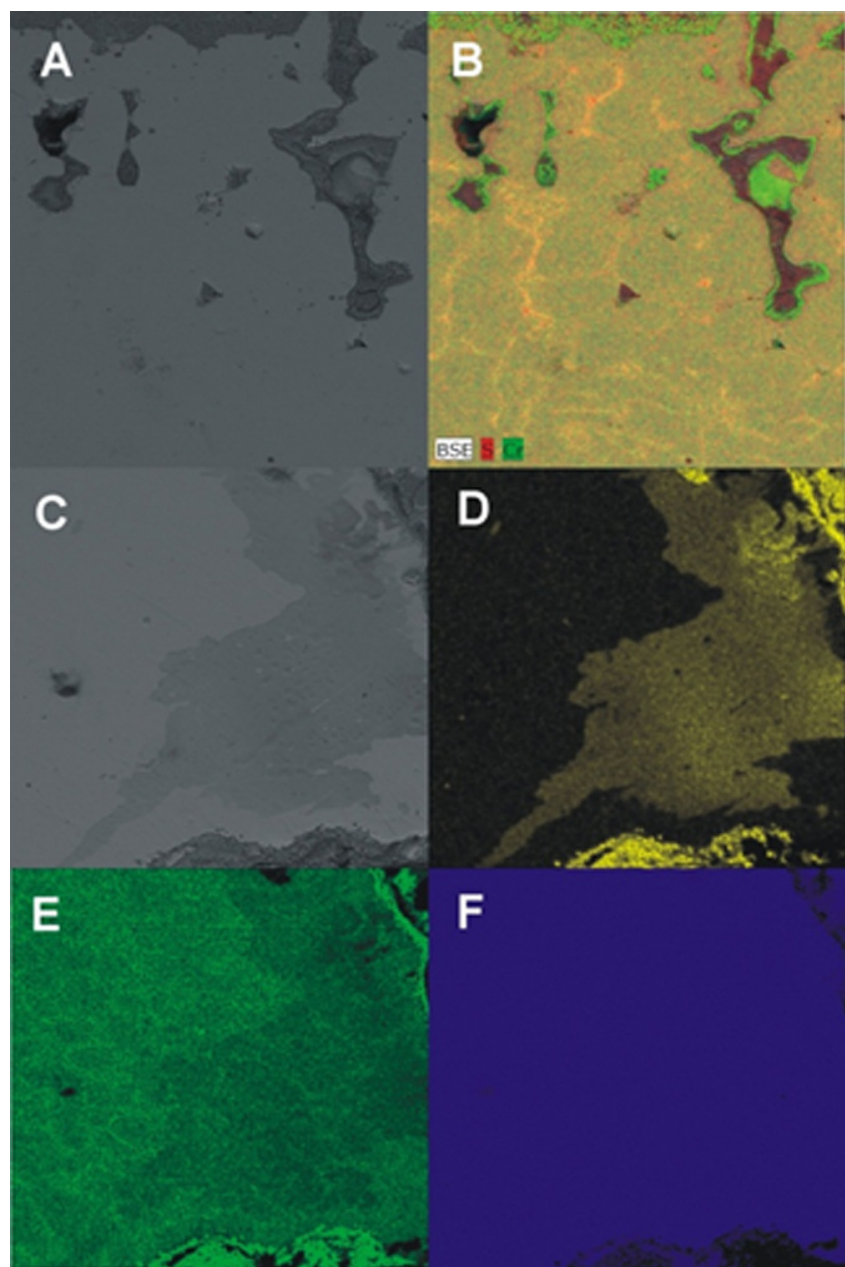

Figura 4. Mapeamento desenvolvido por EDS: A) - região indica corrosão generalizada. B) - Para o crômio e o enxofre. C) - Região escura indicando corrosão generalizada. D) - Para o oxigênio. E) - Para o crômio na mesma região da Figura $4 D$. F) - Para o ferro na mesma região da Figura $4 D$

tectada a presença generalizada do mesmo; já a Figura 4D representa o mapeamento por EDS feito para o oxigênio e ferro, onde se nota uma grande concentração destes elementos, muito provavelmente combinados na forma de $\mathrm{FeO}\left(\mathrm{ou}_{\mathrm{Fe}} \mathrm{O}_{3}\right.$ ) impregnado na superfície. As Figuras 4E e 4F mostram o mapeamento por EDS para os elementos crômio e ferro na amostra do aço F138 ensaiado em Ringer Lactato. Através dos resultados expressos nas Figuras 4E e 4F tem-se a comprovação de que o enriquecimento do teor de crômio se deve à perda na composição do ferro, que foi liberado do material na forma iônica para a solução eletrolítica.

Um fato relevante observado durante os ensaios eletroquímicos, após a aplicação dos ciclos de oxidação-redução, foi o aparecimento de um precipitado amarelo-esverdeado que variou em quantidade conforme o tempo de ensaio eletroquímico, na solução de Ringer Lactato. Este efeito está em consonância com os resultados de Afonso, ${ }^{14}$ que descreve a existência de precipitado gelatinoso sobre a superfície da amostra de aço inoxidável após o ensaio de polarização cíclica potenciodinâmica em solução de meio de cultura celular (MEM).

A Tabela 3 mostra o resultado das análises obtidas por espectroscopia de emissão ótica com plasma induzido, dos precipitados na solução de Ringer Lactato correspondentes aos tempos de ensaio estabelecidos para os aços em estudo, e mostra ainda o $\mathrm{pH}$ medido em cada ciclo de ensaio. Estes resultados comprovam que houve intenso deslocamento de elementos químicos dos implantes para a solução de Ringer Lactato. Dentre os íons metálicos liberados para o precipitado, o níquel proveniente do aço F138 se destaca pela elevada porcentagem presente no precipitado, da ordem de 35 vezes maior que a quantidade de níquel liberado da liga ISO 5832-9, enquanto que os demais íons importantes como, por exemplo, ferro e crômio, apresentaram valores da ordem de 5 vezes maior para o ferro e 7 vezes maior para o crômio no F138 em relação ao ISO 5832-9. Walzack e colaboradores ${ }^{15}$ estudaram a morfologia do aço inoxidável 316L e não encontraram a presença de níquel dentre os produtos da corrosão desse material; por outro lado, Kim e colaboradore ${ }^{16}$ determinaram a presença de íons molibdênio e níquel dentre os produtos da corrosão do aço 316L. Estudo semelhante foi desenvolvido por Staffolani e colaboradores, ${ }^{17}$ que investigaram por espectroscopia de emissão atômica o desprendimento diário desses íons por fios ortodônticos de aço 304 e 316 em meio ácido, e concluíram que os teores de íons metálicos, notadamente o níquel e o crômio liberados, apresentaram valores inferiores aos ingeridos por uma pessoa em uma dieta normal, que corresponde a $150 \mu \mathrm{g} / \mathrm{dia}$. Os resultados encontrados no presente trabalho contradizem as pesquisas anteriores ${ }^{15,17}$ por terem sido observados teores de níquel do aço F138, liberados para a solução de Ringer Lactato, sendo que tais teores foram aumentados com o tempo de ensaio. Considerando-se que no organismo humano a liberação de íons metálicos de implantes ocorre por processos eletroquímicos, conforme a Reação 2, os mesmos podem atingir valores de concentração que possivelmente provocam o comprometimento biológico, físico e químico do sistema implante-tecidos de seus portadores. Kim e colaboradore ${ }^{16}$ identificaram, in vitro, um aumento no índice de citotoxidade do aço inoxidável com a liberação de íons de níquel. Os autores afirmam que estes íons liberados pelo processo de corrosão eletroquímica têm a capacidade de interagir com os tecidos por meio de diferentes mecanismos; consequentemente, funções biológicas são afetadas, o que pode levar ao aparecimento de efeitos sistêmicos e locais. As reações biológicas acontecem pela interação do íon liberado com os tecidos adjacentes, cujos efeitos aparecem principalmente devido à alergia aos íons metálicos liberados. Eliades e colaboradores ${ }^{18}$ verificaram níveis de níquel e crômio liberados por ligas de aço inoxidável e destacaram especial atenção ao níquel, devido ao fato de que esse elemento tem efeitos carcinogênicos, mutagênicos e citotóxicos.

A Tabela 3 mostra ainda que o aço F138 se mostrou muito mais reativo que o ISO 5832-9, comportamento confirmado pelas Figuras 4C

Tabela 3. Resultados analíticos por espectroscopia de emissão ótica com plasma induzido do precipitado e da solução de Ringer Lactato correspondentes aos períodos de ensaio de polarização cíclica potenciodinâmica

\begin{tabular}{|c|c|c|c|c|c|c|c|c|c|c|c|c|}
\hline & \multicolumn{6}{|c|}{ Solução de Ringer Lactato - $\mu \mathrm{g} / \mathrm{L}$} & \multicolumn{6}{|c|}{ Precipitado - \% em massa } \\
\hline & \multicolumn{3}{|c|}{ F 138} & \multicolumn{3}{|c|}{ ISO 5832-9 } & \multicolumn{3}{|c|}{ F 138} & \multicolumn{3}{|c|}{ ISO 5832-9 } \\
\hline & $4 \mathrm{~h}$ & $16 \mathrm{~h}$ & $64 \mathrm{~h}$ & $4 \mathrm{~h}$ & $16 \mathrm{~h}$ & $64 \mathrm{~h}$ & $4 \mathrm{~h}$ & $16 \mathrm{~h}$ & $64 \mathrm{~h}$ & $4 \mathrm{~h}$ & $16 \mathrm{~h}$ & $64 \mathrm{~h}$ \\
\hline $\mathrm{Cr}$ & 20,3 & 14,4 & 18,8 & 58,6 & 19,6 & 20,8 & 1,2 & 2,2 & 1,9 & $657 \mathrm{mg} / \mathrm{kg}$ & 0,3 & 0,53 \\
\hline $\mathrm{Fe}$ & 243 & 34,9 & 97,7 & 60,6 & 61,5 & 64,2 & 0,85 & 1,7 & 1,4 & 0,17 & 0,31 & 0,4 \\
\hline $\mathrm{Ni}$ & 336 & 68,6 & 49,9 & $1,4 \mathrm{mg} / \mathrm{L}$ & $2,7 \mathrm{mg} / \mathrm{L}$ & $2,9 \mathrm{mg} / \mathrm{L}$ & 8,9 & 17,5 & 14,7 & 0,25 & 1,6 & 3,3 \\
\hline $\mathrm{pH}$ & 6 & 5,7 & 5,5 & 6 & 5,7 & 5,5 & & & & & & \\
\hline
\end{tabular}


e 4D, que retratam a intensa formação de pites na solução de Ringer Lactato. A literatura consultada não apresentou nenhuma conclusão a respeito do comportamento corrosivo da solução de Ringer Lactato, mais acentuado que o da solução de $\mathrm{NaCl}$ no ensaio eletroquímico. Todos os trabalhos que estudaram comparativamente as duas soluções apresentaram os mesmos resultados da presente pesquisa, ou seja, a solução de Ringer Lactato se mostrou mais corrosiva que a solução $\mathrm{NaCl} 0,11$ mol L ${ }^{-1} \cdot{ }^{19}$ A solução de Ringer Lactato aproxima-se estreitamente daquela dos líquidos extracelulares, sendo frequentemente usada, por exemplo, na reposição de líquidos no caso de pré-eclâmpsia grave, na desidratação, entre outros; a literatura recomenda cautela ao se administrar lactato de sódio aos pacientes, uma vez que o principal uso do medicamento é a diluição do sangue, em casos onde há perda desse fluido, de modo a evitar o choque hipovolêmico. ${ }^{20}$

Embora haja menção de alguns pesquisadores sobre a formação de um resíduo sólido, nenhum deles identificou, como neste trabalho, os elementos metálicos presentes no precipitado, onde os valores de níquel e ferro possivelmente interagiram com o organismo dos pacientes portadores dos implantes, principalmente os fabricados em aço inoxidável F138, que foram removidos.

Os resultados de polarização cíclica potenciodinâmica obtidos neste trabalho apontam para a necessidade de um cuidado extremo com o uso de alguns tipos de aços em implantes, principalmente em pacientes com problemas de acidose, patologia que tem como tratamento a introdução intravenosa do Ringer Lactato, ${ }^{20}$ visto que tal quadro pode resultar em uma rápida oxidação superficial da mesma e um consequente início de inflamação crônica no organismo do paciente.

Por fim, o Conselho Nacional do Meio Ambiente - CONAMA ${ }^{21}$ afirma que o íon níquel no organismo humano é prejudicial em valores acima de $25 \mu \mathrm{g} / \mathrm{L}$ devido ao grande potencial cancerígeno deste elemento, ${ }^{19}$ o que faz com que o aço F138 seja o mais estudado como material para implante ortopédico permanente, visto que os teores de níquel encontrados na solução de Ringer Lactato, após o ensaio de polarização cíclica potenciodinâmica, mostrados na Tabela 3, bem como no precipitado encontrado neste ensaio, são superiores aos indicados. Tal liga, além da liberação de íons níquel, também permite uma grande liberação de íons ferro, que podem causar reações biológicas adversas ao paciente, levando-o ao insucesso da cirurgia e à necessária remoção do implante antes do tempo mínimo previsto. Desta forma, os resultados aqui descritos indicam uma necessidade premente de estabelecer-se uma normatização das regras acerca do uso de ligas em implantes cirúrgicos. Assim, os presentes resultados sugerem que os hospitais devem optar pelo aço ISO 5832-9 na aplicação de um implante para uso prolongado no organismo humano e, ainda, a conveniência de solicitarem, dos fornecedores, certificados que atestem a composição do aço.

\section{CONCLUSÕES}

O ensaio de polarização cíclica potenciodinâmica demonstrou que o aço ISO 5832-9 se apresenta muito mais resistente à corrosão em meios que simulam fluidos biológicos do que o aço F138, confirmando pesquisas anteriores. ${ }^{2,6,8}$ Esta propriedade é principalmente atribuída ao aumento da estabilidade do filme passivo, favorecida pela presença do nitrogênio em solução sólida no aço ISO 5832-9. As propriedades eletroquímicas, como elevada resistência à corrosão por pites e a baixa densidade de corrente de corrosão passiva apresentadas pelo aço ISO 5832-9 permitem a este material uma menor liberação de metais. Neste caso, tanto o níquel, presentes em menor porcentagem e classificados como cancerígeno, ${ }^{18}$ quanto o ferro, gerados por processos de degradação química, através da corrosão localizada ou da generalizada.
A partir dos dados obtidos pode-se concluir ainda que implantes ortopédicos permanentes, produzidos em aço inoxidável ISO 5832-9, aferem maior estabilidade química e mecânica, em meios como os dos fluidos corpóreos, reduzindo os riscos de inflamações crônicas ou ainda a falhas mecânicas do implante, uma vez que os pites localizados podem ser causadores de microfissuras.

\section{AGRADECIMENTOS}

Ao Setor de Caracterização Tecnológica do Centro de Tecnologia Mineral - CETEM, pelo uso dos equipamentos (ICP, emissão ótica e MEV), à ArcelorMittal Juiz de Fora pelo uso do equipamento de emissão ótica, ao Departamento de Metalurgia do Instituto Federal de Juiz de Fora pelo uso do laboratório de corrosão e ao CNPq pelo suporte financeiro.

\section{REFERÊNCIAS}

1. Disegi, J. A.; Eschbach, L.; Revista Injury-International Journal of the Care of the Injured 2000, 31, D14.

2. ASTM STP 1438; Winters, G. L.; Nutt, M. J., eds.; American Society for Testing and Materials: West Conshohocken, 2003.

3. Sourisseau, T.; Chaveau, E.; Baroux, B.; Corros. Sci. 2005, 47, 1097.

4. Padillha, A. F.; Guedes, L. C.; Aços Inoxidáveis Austeníticos: Microestruturas e Propriedades, $1^{\text {a }}$ ed., Hemus: Curitiba, 1994.

5. Cavalcanti, E. H. S.; Souza, S. M. C.; Ferreira, C. A.; Campos, M. M.; Abud, I. C.; Palmeira, L.; Anais do $22^{\circ}$ Congresso Brasileiro de Corrosão, Salvador, Brasil, 2002.

6. Terada, M.; Tese de Doutorado, Instituto de Pesquisas Energéticas e Nucleares, Universidade de São Paulo, Brasil, 2008.

7. Giordani, E. J.; Guimarães, V. A.; Pinto, T. B.; Ferreira, I.; International Journal of Fatigue 2004, 26, 1129.

8. Cahoon, J. R.; Bandyopadhya, R.; Tennese, L.; J. Biomed. Mater. Res. 1975, 6, 259.

9. Landoulsi, J.; Genet, M. J.; Richard, C.; Kirat, K.; Pulvin, S.; Rouxhet, P. G.; J. Colloid Interface Sci. 2008, 318, 278.

10. Bandy, R.; Cahoon, J. R. E.; Corrosion 1977, 33, 204.

11. Sumita, M.; Hanawa, T.; Teoh, S. H.; Mater. Sci. Eng. 2004, 24, 753.

12. Rondelli, G.; Torricelli, P.; Fini, M.; Giardino, R.; Biomaterials 2005, 26,739 .

13. Sedriks, A. J.; Corrosion 1986, 42, 376.

14. Afonso, M. L. C. A.; Tese de Doutorado, Universidade de São Paulo, Brasil, 2006.

15. Walzack, J.; Shahgaldi, F.; Heatley, F.; Biomaterials 1998, 19, 229.

16. Kim, Y. S.; Yoo, Y. R.; Sohn, C. G.; Oh, K. T.; Kim, K. N.; Yoon, J. H.; Kim, H. S.; Materials Science Forum 2005, 475, 2295.

17. Staffolani, N.; Damiani, F.; Lilli, C.; Guerra, M.; Staffolani, N. J.; Belcastro, S.; Locci, P.; Journal of Dentistry 1999, 27, 449.

18. Eliades, T.; Pratsinis, H.; Kletsas, D.; Eliades, G.; Makou, M.; Am. J. Orthod. Dentofacial Orthop. 2004, 125, 24.

19. Villamil, R. F. V.; Aranha, H.; Afonso, M. L. C. A.; Mercadante, M. T.; Agostinho, S. M. L.; Revista Brasileira de Ortopedia e Traumatologia 2002, 37, 471 .

20. Trissel, L. A.; Handbook on injectable drugs, $15^{\text {th }}$ ed., American Society of Health: London, 2008; Beckwith, M. C.; Feddema, S. S.; Barton, R. G.; Graves C.; Hospital Pharmacy 2004, 39, 225.

21. Brasil; Resolução do Conselho Nacional do Meio Ambiente CONAMA n. ${ }^{\circ}$ 20/86, de 18/6/1986, Diário Oficial [da república do Brasil], Brasília, 30/6/1986. 